\title{
Assessing Psychologists' Knowledge and Attitudes Toward Near-Death Phenomena
}

\author{
Barbara A. Walker, Ph.D. \\ Eastern Illinois University \\ Robert D. Russell, Ed.D. \\ Southern Illinois University
}

\begin{abstract}
Nina Thornburg's (1988) Near-Death Phenomena Knowledge and Attitudes Questionnaire was distributed to 326 randomly selected Illinois psychologists. Of 117 usable questionnaires received, the mean score for knowledge questions was 7.5 of a maximum score of 18. Respondents were most knowledgeable about near-death elements of peace, out-of-body transcendence, and tunnel/light phenomena. The mean score for the attitude portion of the instrument was 61.3 of a maximum score of 85 points for the most positive attitude. Seven percent of the respondents indicated having had a near-death experience, $19 \%$ indicated having counseling near-death experiencers, and $28 \%$ indicated having had personal contacts with an experiencer.
\end{abstract}

Although death is an inevitable reality of life, what occurs after the body's physiological functions have ceased remains a mystery. Perhaps to attain some control over and understanding of our forthcoming demise, human beings throughout history have recorded stories of characters who claim to have actually died and returned to inform us about the afterlife (Kastenbaum, 1979; Audette, 1982).

Dr. Walker is with the Department of Health Studies at Eastern Illinois University, and Dr. Russell is with the Department of Health Education at Southern Illinois University. Requests for reprints should be addressed to Dr. Walker at the Department of Health Studies, Lantz Building, Eastern Illinois University, Charleston, ㄴ 61920. 
While these near-death experiences (NDEs) have been described for more than 4000 years, people have only begun to look at the subject from a scientific perspective during the past 25 years. Despite the expanding attention near-death phenomena have received recently, health care professionals and family members often cannot relate to the concept of an NDE, choosing to discount the experiencer's claims as a stress-induced or drug-induced illusion. There are a number of variables that account for this unwillingness to listen, many of which are associated with our Western cultural fear of death, as well as the inability and unwillingness to relate to a phenomenon that suggests another realm of existence.

Although health care professionals are, perhaps, most directly accessible to near-death experiencers immediately following near-fatal encounters, little has been done in the way of researching this population. Nurses recently have begun to evaluate existing knowledge and attitudes within their profession (Orne, 1986; Papowitz, 1986; StromPaikin, 1986; Thornburg, 1988). Literature is scant regarding knowledge and attitudes of other health care professionals concerning this topic.

The purpose of this study was to determine the knowledge and attitudes of registered psychologists toward near-death phenomena. Secondary purposes of this study were (a) to determine how many of these psychologists had been confronted by clients who claimed to have had an NDE, and (b) to determine how many psychologists have themselves undergone an NDE.

\section{Need for the Study}

Approximately eight million adults have undergone an NDE within the United States (Gallup, 1982). As noted by Kenneth Ring (1984), a number of these experiencers encounter depressive aftereffects due to a lack of sensitivity and understanding on the part of health care professionals and family members. It is obvious that the needs of many near-death experiencers are not being served at present. Since nurses, physicians, psychiatrists, psychologists, clergy, social workers, family members, and health educators are the most likely populations to come into contact with experiencers immediately following an NDE, it might be beneficial to investigate their knowledge and attitudes regarding this topic. As psychologists are a likely population for dealing with suicide and death-related stress, information from this study could prove to be professionally beneficial. 
Based on informal observation and preliminary research, it appears that individuals merely exposed to information about NDEs develop a diminished fear of death (Ring, 1982). This change is particularly evident when direct contact is made with a near-death experiencer. As Ernst Becker (1973) noted, our lives are dominated, both consciously and unconsciously, by the fear of death. We often waste potentially productive energy worrying about death. Knowledge of NDEs has also been used to deter suicide (McDonagh, 1979; Ring, 1980, 1982; Ring and Franklin, 1981-1982).

The implications for near-death studies are evident here, particularly in the area of mental health and death education. Health educators can inform health care professionals and the general public about this topic, thus "normalizing" the phenomenon. In that way, neardeath experiencers in need of counseling may feel more comfortable about seeking therapy, and therapists and other mental health specialists will be better prepared to meet the emotional needs of the client.

\section{Method}

\section{Subjects}

The population sampled for this study was drawn from a State of Illinois Department of Registration and Education listing of 2,027 registered psychologists. A total of 326 questionnaires were distributed to a randomly selected sample from this list, and 117 usable questionnaires were obtained for a 36 percent return rate.

\section{Instrument}

To determine the knowledge and attitudes of registered psychologists toward near-death phenomena, Nina Thornburg's (1988) NearDeath Phenomena and Attitudes Questionnaire was used. The pilot study used in developing this instrument elicited responses from a sample of convenience consisting of 20 registered nurses employed within the Intensive Care and Coronary Care Units of a large Midwestern medical center.

Thornburg used a panel of experts selected from nursing, sociology, and psychology in establishing the content validity of the instrument, and knowledge and attitude portions of the instrument were tested for 
internal consistency. Data were factor analyzed to establish construct validity for the knowledge and attitude portions of the instrument. Only questions with a factor loading greater than .51 were retained. Likewise, Cronbach alpha reliability coefficients were obtained in determining internal consistency of each subscale obtained from factor analysis.

Factors and corresponding alpha coefficients for knowledge questions included: knowledge of the NDE (.84), causes/correlates of the NDE (.77), concomitant events/activities associated with NDEs (.72), and knowledge about persons' perceptions (.72). Factors and alpha coefficients for questions regarding attitude toward NDEs included: reporting NDEs (.90), factors influencing/affecting care (.70), psychological implications of NDEs (.80), and patient care activities surrounding NDEs (.73). Factors and alpha coefficients for questions regarding attitudes toward care of clients included: importance of nurses' attitudes to patient care (.92), patients' perceptions of their NDEs (.76), and nurses' awareness of the effect of NDEs on patients (.70).

Minor modifications in the original instrument made it easier to code and more applicable to registered psychologists. The first of these modifications included re-labeling each set of questions by section for further clarification. We also added questions pertaining to the subjects' exposure to near-death experiencers as clients, subjects' exposure to close friends and family who have reported an NDE, subjects' active involvement in counseling clients, number of client contact hours per week, and type of work setting.

The modified instrument used in this study consisted of 7 general information questions, 18 cognitive questions, 17 affective questions, 15 professional questions, and 11 demographic questions. According to Thornburg (1988), components of the knowledge scale included elements of the NDE, predisposing and precipitating factors, sequelae of the NDE, and possible etiologies of NDEs. Components of the attitude scale included possible etiologies of the NDE, near-death education, health care participation, and health care providers' roles in dealing with near-death phenomena.

General knowledge and information items included open-ended questions for additional clarification and questions requiring a "yes" or "no" response. Specific knowledge items were presented in a format requiring a "true," "false," or "undecided" response. Correct responses were given a numerical value of one, and incorrect or undecided responses were scored as zero.

Attitude questions were composed of positive and negative statements related to near-death phenomena and care of near-death experi- 
encers as clients. Respondents chose from a range of responses including "strongly agree," "agree," "uncertain," "disagree," and "strongly disagree." Each response was given a number value of from one to five, with positive responses, as determined by Thornburg, scored so that an answer of "strongly agree" was assigned a value of five, and negative responses scored so that an answer of "strongly disagree" was assigned a value of five. Assignment of "correct" responses to knowledge questions, and "positive" and "negative" labels to attitude questions, followed the scoring procedure used by Thornburg in her original instrument (1988).

\section{Data Collection}

The instrument was mailed to 326 registered psychologists randomly selected by a standard computer algorithm from the Illinois Department of Registration and Education listing. A cover letter, instrument, self-addressed postcard, and self-addressed return envelope were provided for each participant. The cover letter explained the purpose of the study, the estimated time to complete the questionnaire, a requested deadline date, and instructions on returning the self-addressed stamped envelope and postcard.

Participants were asked to return the postcard separately when returning the completed questionnaire, so that participating subjects' names could be removed from the resampling list. A space was also included on the postcard asking respondents if they would like to obtain the results of the study and a list of clinical applications involving near-death phenomena. A reminder postcard was sent to subjects 10 days after the first mailing, and an additional follow-up mailing of the original packet was forwarded to those failing to return a completed instrument within 10 days of the reminder postcard.

\section{Results}

\section{Respondents}

A total of 117 usable questionnaires was received, for a response rate of 36 percent. Of the participating sample, $58 \%$ were male and $41 \%$ female, and $1 \%$ did not indicate gender. The mean age for all respondents was 46 years. The majority of respondents had earned a Doctor of Philosophy degree (78\%), and most were clinical psychologists (81\%). 
The largest percentage worked in private practice $(38 \%)$, and $81 \%$ were currently counseling clients. The mean number of clinical hours for all respondents was 16 hours a week, while the average for those currently counseling clients was 19 hours. Approximately half of all respondents attended a church or synagogue (49\%), with the majority belonging to the Protestant (37\%) and Jewish (20\%) faiths.

\section{Knowledge}

The mean score for knowledge questions was 7.5, with a range from 0 to 18. Respondents were most knowledgeable about questions dealing with the NDE element of "peace," with subsequent belief in an afterlife, with the similarity among experiencers' descriptions of NDEs, and with experiencers' being told or deciding to return to the physical body from the out-of-body state. In their written descriptions of NDEs, respondents most often mentioned out-of-body transcendence, and tunnel/light phenomena. Respondents were least knowledgeable about questions dealing with the relationships between drug use and NDEs, and between attempted suicide and NDEs.

While the majority (88\%) of respondents indicated that they were familiar with the term "near-death experience," many mentioned in their written descriptions of NDEs only one of the 15 elements described by Raymond Moody when he coined the term (1975). Based on the limited content of respondents' written descriptions of NDEs and their mean knowledge score (7.5), it is evident that respondents were indeed familiar with the term NDE but may have lacked a comprehensive understanding of the subject. There were no significant differences between male and female respondents on knowledge scores.

\section{Attitudes}

The mean score for the attitudes portion of the instrument was 61.3 of a possible 85 points, with a range from 0 to 81 . Higher scores represented more positive attitudes toward near-death phenomena.

A positive correlation was found between knowledge scores and attitude scores of all respondents $(r=.54, p<.0001)$, and separately for males $(r=.52)$ and females $(r=.60)$. There were no significant differences between male and female respondents on attitude scores. Approximately $20 \%$ of the variance between knowledge and attitude scores was attributable to age $(r=.20, p=.0001)$. 
A total of eight participants (7\%) indicated having personally had an NDE. However, based on the inadequate content of their written NDE accounts, that incidence rate may be slightly exaggerated. Likewise, $19 \%$ of the psychologists reported having counseled clients who had NDEs, and $28 \%$ indicated having had personal contact with a neardeath experiencer, either as a client or as a friend or relative. Neither knowledge nor attitude scores were significantly correlated with having had an NDE or having been exposed to a near-death experiencer.

\section{Discussion}

Based on the analysis of these data and subjective comments of our respondents, it appears that participating psychologists demonstrated limited knowledge of near-death phenomena, but maintained a moderately positive attitude toward the topic. However, data may have been influenced by confusion about the definition of a "near-death experience." Current literature on the subject has come to define NDEs primarily in accordance with descriptive elements enumerated by Moody (1975) and Ring $(1980,1984)$. The literal meaning, as indicated by some of the psychologists' descriptions, may also include any circumstance in which a person has come close to death. Therefore, care should be taken in defining knowledge and attitude based on the label "NDE" alone, the literal meaning of which is not limited to transcendental phenomena.

There were also a number of criticisms raised concerning the questionnaire itself. The nature of the introductory sample questions may have biased responses in that they reflected positive attitudes toward near-death phenomena. The limited number of questions within each section of the instrument may have restricted its ability to demonstrate comprehensive individual knowledge and attitudes. Although the research instrument was found to have internal consistency, its overall validity is open to question.

In general, there were no significant differences in knowledge and attitude scores based on having had an NDE (7\% of respondents) or having counseled clients with NDEs (19\% of respondents). Perhaps this was due to the fact that the average respondent was 46 years old, while widespread media exposure of NDEs has been present only for the past 10 to 15 years, so that information and resources may not have been available at the time of the NDE. There were also no significant differences in knowledge and attitude scores based on age and gender, and knowledge scores had only a moderate positive influence on attitude scores. 
Based on subjective comments, there was also a wide range of feelings expressed toward the topic itself, from sympathy to antagonism. Nevertheless, many respondents indicated an interest in obtaining information relative to the clinical applications of near-death phenomena. Some psychologists cautioned, however, that this topic should be of no greater relevancy than other areas of personal concern. Although that point is well taken, NDEs have not yet become "normalized" within the field of psychology or any other health care profession.

Considering that an estimated eight million Americans have experienced NDEs, and in light of the fact that $19 \%$ of responding psychologists indicated having been told of NDEs by clients, the potential for professional exposure to these phenomena is high. Likewise, as our elderly population continues to grow and improved methods of medical intervention are applied, the potential for an increase in NDEs seems probable. Therefore, it is evident that this is an area of clinical concern that should warrant educational involvement within the fields of health education, psychology, and related human service professions. Such efforts would facilitate better clinical care, so that the emotional needs of clients who have undergone NDEs may be recognized and served.

\section{References}

Audette, J.R. (1982). Historical perspectives on near-death episodes and experiences. In C.R. Lundahl (Ed.), A collection of near-death research readings (pp. 21-43). Chicago, IL: Nelson-Hall.

Becker, E. (1973). The denial of death. New York, NY: Free Press.

Gallup, G., Jr. (1982). Adventures in immortality: A look beyond the threshold of death. New York, NY: McGraw-Hill.

Kastenbaum R. (1979). Between life and death. New York, NY: Springer.

McDonagh, J. (1979). Bibliotherapy with suicidal patients. Paper presented at the American Psychological Association 87th Annual Convention, New York, NY. (Reprinted in Anabiosis [East Peoria], 1(2), 7-9.

Moody, R.A., Jr. (1975). Life after life Covington, GA: Mockingbird.

Orne, R.M. (1986). Nurses' views of NDEs. American Journal of Nursing, 86, 419-420.

Papowitz, L. (1986). Deathlife. American Journal of Nursing, 86, 416-418.

Ring, K. (1980). Life at death: A scientific investigation of the near-death experience. New York, NY: Coward, McCann and Geoghegan.

Ring, K. (1982). Near-death studies: A new area of consciousness research. Storrs, CT: International Association for Near-Death Studies.

Ring, K. (1984). Heading toward omega: In search of the meaning of the near-death experience. New York, NY: William Morrow.

Ring, K., and Franklin, S. (1981-1982). Do suicide survivors report near-death experiences? Omega, 12, 191-208.

Strom-Paikin, J. (1986). Studying the NDE phenomenon. American Journal of Nursing $86,420-421$.

Thornburg, N.R. (1988). Development of the Near-Death Phenomena Knowledge and Attitudes Questionnaire. Journal of Near-Death Studies, 6, 223-239. 